\title{
Reliability-Based Estimation of Traffic Interruption Probability due to Road Waterlogging
}

\author{
Manuel Contreras-Jara, ${ }^{1}$ Tomás Echaveguren (DD, ${ }^{1,2}$ José Vargas Baecheler, ${ }^{1}$ \\ Alondra Chamorro Giné $(1),{ }^{2,3}$ and Hernán de Solminihac Tampier ${ }^{3,4}$ \\ ${ }^{1}$ Laboratory of Transportation Systems Management (GESITRAN), Departamento de Ingeniería Civil, \\ Facultad de Ingeniería, Universidad de Concepción, Edmundo Larenas 219, Concepción, Chile \\ ${ }^{2}$ National Research Center for Integrated Natural Disaster Management (CIGIDEN), CONICYT/FONDAP/15110017, \\ Avda. Vicuña Mackenna 4860, Santiago, Chile \\ ${ }^{3}$ Department of Construction Engineering and Management, School of Engineering, Pontificia Universidad Católica de Chile, \\ Avda. Vicuña Mackenna 4860, Santiago, Chile \\ ${ }^{4}$ Latin American Center of Economic and Social Policies (CLAPES UC), Avda. Libertador Bernardo O’Higgins 440, \\ Piso 13, Santiago, Chile
}

Correspondence should be addressed to Tomás Echaveguren; techaveg@udec.cl

Received 31 March 2018; Revised 14 June 2018; Accepted 2 July 2018; Published 29 July 2018

Academic Editor: Nirajan Shiwakoti

Copyright (c) 2018 Manuel Contreras-Jara et al. This is an open access article distributed under the Creative Commons Attribution License, which permits unrestricted use, distribution, and reproduction in any medium, provided the original work is properly cited.

Floods affect road infrastructure physically and operationally, increase road user costs and road agencies cost, and eventually isolate communities. The research of the effect of floods on vehicular circulation is mainly focused on the stability of vehicles. There are few studies related to the regime of still water in the trafficability. In still water, the speed flow is low and does not compromise the vehicle stability. In this case, the vehicle's wading height becomes relevant. This article proposes a procedure to estimate the traffic interruption probability caused by floods in roads, considering the still water regime. The procedure uses the first-order reliability method to estimate traffic interruption probabilities, based on the difference between the probability density functions (PDF) of still water depth (or waterlogging depth) and vehicle wading height. A specific procedure to estimate the PDF of wading height based in the geometric characteristics of light and heavy vehicles was developed. The PDF for water depth was estimated using water level profile simulation software. The procedure was applied in the south of Chile. The PDF of wading height was obtained from a record of 166,155 vehicles tagged in open road tolls. The PDF of waterlogging depth was obtained from discharge records of 10 fluviometric stations. 42 probability curves were obtained for six vehicle classes and return periods between 4 and 500 years. The still water depth obtained for traffic interruption probability of 1,0 varied between 70 and $90 \mathrm{~cm}$ for light vehicles and between 110 and $150 \mathrm{~cm}$ for heavy vehicles.

\section{Introduction}

Floods damage the physical highway assets and affected their operations. Floods are caused by high intensity rains in a short period of time and induce a rapid rise in water level, overflowing the river banks [1]. Floods usually erode the river banks, scour and destabilize the pier and footings of bridges, and weaken the rock fill and rip-rap foundations. The waterlogging is defined as a slow increase of the water level that covers the low lands and flood plains at low water flow speed.
If the highways are placed in flood plains, the highways' physical assets experience little damage, but the road network operation can be totally or partially interrupted during and before the rain period, until the water level decreases and the roads can recover the trafficability. The traffic interruption degree depends upon if the water level over the roadway is higher or lower than the vehicle's wading capability and if the water speed is enough or not to destabilize or drag the vehicle. The wading capability depends on the wading height, which is the maximum water level at which a vehicle can 
ride without affecting the engine, brakes, and the heating, ventilation, and conditioning system (HVAC) and without loss stability because of floating and sliding. Each type of vehicle has a specific wading height. If the water level is lower than the wading height and the water speed is low, vehicles can ride over the flooded road at a reduced speed, increasing the travel time and the operating cost. The consequence is a reduction of the traffic quality in terms of the Level of Service (LOS) of the road, which is measured using the average travel speed and the spend-time-following vehicles in twolane rural roads and in multilane highways in terms of the traffic density [2]. Also, if the water level and speed are high, vehicles are destabilized and cannot pass through the flooded road. In this case, the loss of LOS is total. Therefore, predicting the possibility that a vehicle can ride over a flooded road depends on the vehicle characteristics and the magnitude of the flood.

There exist several models to predict the water depth over the roadway because of a flood: ad hoc models; hydrologicalhydraulic (H-H) 1D, 2D, and 3D models; and GIS-based models [3]. The ad hoc models are empirical and estimate flooded areas (named blue spots) based on historical data. These allow creating flood maps and are an efficient alternative if it is not possible to calibrate more sophisticated models [4-6]. The $\mathrm{H}-\mathrm{H}$ 1D models used the river and bank's topography, the water flow, and the hydraulic regime to calculate the water level profile and the flooded surface. Examples of this type of models are HEC-RAS and MIKE11 [7, 8]. The H-H 2D models also need data of the flooded area, the ground roughness, the river slope, the rain intensity, and terrain digital models [9]. Examples of these types of models are HEC-RAS 2D, IBER, and MIKE FLOOD [10, 11]. The H-H 3D models estimate the flow speed too but are intensive in data needs because of considering advective and convective transport, the sediment transport, and the wave effect to estimate the water level profile [12]. The GIS-based models integrate some characteristics of the $\mathrm{H}-\mathrm{H}$ models to the GIS capabilities but also allow estimating physical and economic damage due to floods particularly in urban areas. Examples of these models are HEC-FDA, HAZUS-HM, Damage Scanner, Flemish Model, and Multicolored Manual among others [1317].

These models previously described only estimate the water depth over the roadway. The water depth depends on the return periods, the river, and floodplains' topography. Therefore, it is plausible to assume that this variable can be characterized with a probability density function. However, to study the probability of traffic interruption, it is also necessary to calculate the wading height, which is a specific property of each vehicle type included in a vehicle fleet. Each type of vehicle has its own engine, brake, and HVAC system, as well as a tire diameter and ground clearance. Therefore, there is a probability function that describes the vehicle's wading height of each brand and model of light cars, pick-up, SUV, trucks, and buses. Because the wading height and the water depth are random, the traffic interruption must be estimated using probabilistic models. In this sense, this paper proposes and applies a procedure to estimate the traffic interruption probability by integrating both variables: still water depth (also named waterlogging depth) and wading height, considering their randomness. In the first part of the paper, the effect of flooding over highway assets is discussed. Next, an analytical procedure based on the first-order reliability method (FORM) is presented. The procedure included the estimation of probability density function (PDF) of water depth and wading height using discharge data and individual vehicle data, respectively. The procedure was applied to a case study in the middle-south of Chile, where the road waterlogging is recurrent year after year.

\section{Effects of Floods on Road Infrastructure, Traffic, and Vehicles}

The floods affected the road infrastructure that crosses rivers and those parallel to the river banks, such as roads with cut-fill slopes, those placed in floodplains and in flat ground with low infiltration capacity. The damage to the infrastructure is structural and functional. The structural damage is produced by hydraulic erosion. The erosion wake crosses slopes, increasing the scour in bridges and weakening river bank protections. The floods also affect the drainage system, compromising its capacity of moving the water from slopes, embankments, and road subgrades. In the long term this effect reduces the pavement's durability. The functional damage is manifested in a reduction of the LOS of the road network. This reduction can be induced by partial destruction of the pavement surface, reduction of the lane width, loss of lanes available, or roadway flooding. Functional damage does not necessarily interrupt traffic but reduces the average travel speed and eventually only certain type of vehicles can pass through flooded roads. If the traffic is totally interrupted, communities can be isolated if there are no alternative routes.

The level of road traffic interruption caused by floods can be classified in the following scenarios: normal circulation, in which all the vehicle can pass through the flooded road without reducing the speed; restrained circulation, in which all the vehicles can pass through the flooded road but at a low speed; partial interruption, in which only heavy vehicles can pass along the flooded road; and total traffic interruption in which no type of vehicle can pass through the flooded road. The traffic interruption level depends on the magnitude and duration of the flood. It affects the road users, the nonusers, and the highway agencies. Road users experience higher travel times and operating costs, restrained circulation, or road crashes; the nonusers may experience isolation and lack of access to essential or vital services. The highway agency expends additional budget for repairing and/or rebuilding roads, taking a percent of the budget assigned to other maintenance activities, for instance.

If the water covers the roadway, the circulation possibility depends also of the vehicle wading height and weight, the water flow speed, and the water depth over the road. If the water flow speed is low and the wading height is higher (or similar) than the water depth, the vehicle keeps stable, but the HVAC system can be damaged. If the water depth is lower 
than the wading height the vehicle can ride over the flooded road at a low speed. On the contrary, if the water speed flow is high, there exists a water depth threshold that avoids the vehicle destabilization. If the water depth overcomes this threshold, the vehicle loses stability and is dragged by the water flow and driver loses control of the vehicle and traffic is totally interrupted. In this case, the wading height is not applicable, being more important the water depth threshold.

The research available in the literature about the effect of climate on road traffic can be categorized into two groups: (a) studies that analyze the reduction of traffic speed under adverse weather conditions and (b) studies that analyze the effect of flooding on roads due to rainfall. Examples of the first type of study are found in [18-25], where the authors estimate the percentage of reduction of the average travel speed in relation to the intensity of the rain, during the rain and before the flood. The second group of research is classified in two subgroups: (a) studies of vehicle stability in flooded roads and (b) studies of wading capabilities of vehicles in flooded road with a still water regime. The studies of vehicle stability used hydrodynamic models to estimate the water depth and speed threshold than inducing (or avoiding) sliding, toppling, or floating to vehicles [26-31]. Martinez-Gomariz [32] represented in a speed-depth graph all the results existent in the literature. From the summary of Martinez-Gomariz it was concluded that the water depthspeed thresholds that destabilize light cars ranged between 0,4 and $0,7 \mathrm{~m}$ at flow speeds lower than $1 \mathrm{~m} / \mathrm{s}$ and between 0,2 and $0,5 \mathrm{~m}$ at flow speeds between 1 and $6 \mathrm{~m} / \mathrm{s}$. In comparison with the vehicle stability studies, the studies of traffic interruption in still waters are scarce. Pyatkova et al. [33] studied the effect on urban traffic on street flooded with water depths between 0,07 and 2,0 $\mathrm{m}$ and more. They used the software MIKE FLOOD to simulate flood with different return periods and assumed that streets are closed approximately when water depth reaches between 0,5 and 1,0 m. Yin et al. [34] developed in China a similar study. They elaborate flood maps for return periods between 5 and 100 years, with which water depths between $0,05 \mathrm{~m}$ and $0,5 \mathrm{~m}$ and more are obtained. They used a water depth threshold between 25 and $35 \mathrm{~cm}$ to close streets and study the effect over traffic delays. In Australia, Affum et al. [35] used the concept of limit still water depth to warn drivers about the safe crossing of floodways. It is an indirect measure of wading height. The still water depth thresholds used suggested by Affum et al. for light cars and SUV ranged between 0,3 and $0,5 \mathrm{~m}$. However, they recommended more studies to validate it.

\section{Analytical Modelling of Traffic Interruption Probability}

3.1. Conceptual Framework. The traffic interruption model proposed considered the uncertainty of the wading height and waterlogging depth through sigmoidal probability curves. The conceptual model is constituted by the three parts described in Figure 1: (a) estimation of the traffic probability interruption in terms of the wading height and waterlogging depth; (b) estimation of the individual probabilities using FORM; and (c) estimation of the PDF for wading height and waterlogging depth. Each point of the probability curve (Box "a" in Figure 1) is obtained by applying FORM (Box " $\mathrm{b}$ " in Figure 1) and using a limit state function (LSF) that is the difference between the wading height $\left(\mathrm{H}_{\text {wading }}\right)$ and the waterlogging depth $\left(\mathrm{H}_{\text {waterlogging }}\right)$. Both variables are random. The $\mathrm{H}_{\text {wading }}$ randomness is explained by the variability of the vehicles' geometry, engines, HVAC systems, tire diameter, and ground clearance of each vehicle class (light car, pick-up, SUV, trucks, and buses), brands, and models. The $\mathrm{H}_{\text {waterlogging }}$ randomness is explained by the water flow magnitude, the return period, the river topography, and the location of the road in relation to the river.

\subsection{Estimation of the Probability Density Function of Wading} Height. The wading height is defined as the maximum depth of a low-speed water flow at which a vehicle can ride without electric, engine, or HVAC system damage, depending on the vehicle configuration. In a vehicle fleet, there is one wading height for each vehicle brand and model. The vehicle fleet is defined as a set of classes and subclasses existing in a country. Typical vehicle classes and subclasses belonging to a vehicle fleet are shown in Figure 2.

The wading height $\left(\mathrm{H}_{\text {wading }}\right)$ can be obtained using three methods: from manufacturers catalog, by in-field measuring, and by analytical estimates from the geometric properties of vehicles described in the manufacturers' catalog. The analytical procedure is more practical because the manufacturers do not always provide wading height values, and the in-field measurements usually considered small sample sizes that underrepresent the vehicle class, brand, and model present in vehicle fleets. The analytical procedure estimate $\mathrm{H}_{\text {wading,sub-class,brand,model }}$ for each vehicle subclass, brand, and model classified according to Figure 2, using (1) and (2), in which $D_{\text {LL,sub-class,brand,model }}$ (in $\mathrm{mm}$ ) is the external diameter of the tires of each vehicle subclass, brand, and model without considering its deformation because of loads. The values of $D_{L L}$ are obtained from the catalogs of vehicle manufacturers as well as the values of $\mathrm{H}_{\text {wading }}$ if they are available. The parameter $\alpha_{\text {sub-class }}$ of (1) is estimated by adding all the values of $\mathrm{H}_{\text {wading,sub-class,brand,model }}$ and $\mathrm{D}_{\mathrm{LL} \text {,sub-class,brand,model }}$ available in the catalogs for the "V" vehicle subclasses. Therefore, this parameter is constant for each vehicle subclass. Then, introducing the $\alpha_{\text {sub-class }}$ value in (2), the $\mathrm{H}_{\text {wading }}$ for each brand and model of vehicle belonging to each subclass can be obtained.

$$
\begin{aligned}
& \alpha_{\text {sub-class }}=\frac{1}{\mathrm{v}} \sum_{\mathrm{i}=1}^{\mathrm{i}=\mathrm{V}} \frac{\mathrm{H}_{\text {wading,sub-class,brand,model }}}{\mathrm{D}_{\mathrm{LL}, \text { sub-class,brand,model }}} \\
& \mathrm{H}_{\text {wading,vehicle brand and model }} \\
& \quad=\alpha_{\text {sub-class }} \mathrm{D}_{\mathrm{LL}, \text { sub-class,brand,model }}
\end{aligned}
$$



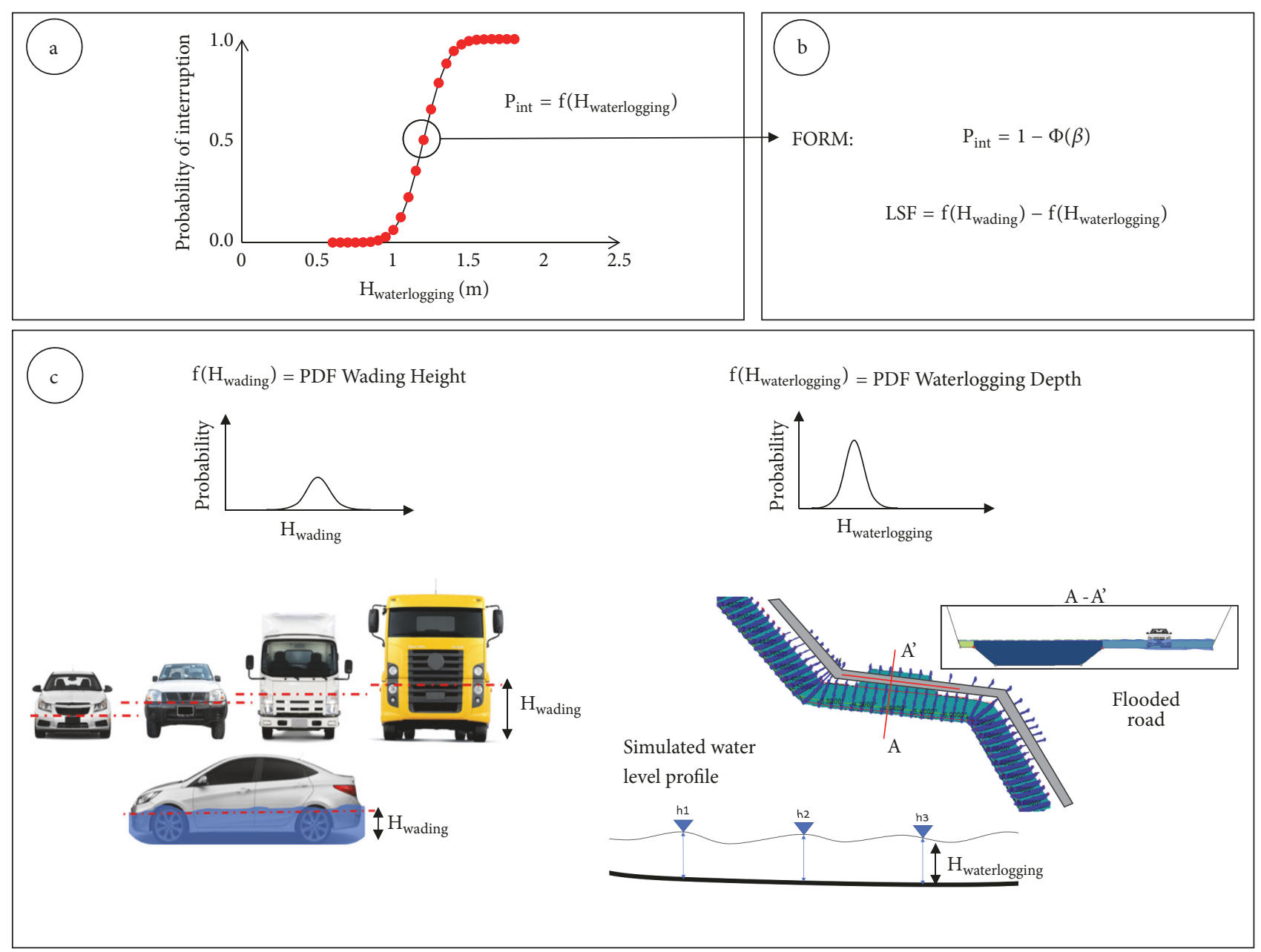

FIGURE 1: Conceptual model for obtaining traffic interruption probability curve caused by waterlogging.

The PDF of $\mathrm{H}_{\text {wading }}$ is estimated using the standard procedure to fit empirical PDF to continuous PDF: (a) to group the data of $\mathrm{H}_{\text {wading }}$ of each vehicle class and subclass; (b) to apply goodness of fit (GoF) tests, such as Kolmogorov-Smirnov, Chi square, Anderson-Darling, or Shapiro Wilks to identify the type of probability distribution; (c) to elaborate a ranking of the adjusted PDF according to the GoF test; (d) to select the probability distribution that best fit the empirical PDF of $\mathrm{H}_{\text {wading }}$; $(\mathrm{d})$ to estimate the parameters associated with the PDF of fitted $\mathrm{H}_{\text {wading }}$.

\subsection{Estimation of the Probability Density Function of Water} Depth. The waterlogging height $\left(\mathrm{H}_{\text {waterlogging }}\right)$ is the difference between the water depth at each river cross-section obtained from the water level profile $(\mathrm{EH}$, in $\mathrm{m})$ and the roadway centerline height of the longitudinal profile (CR, in $\mathrm{m}$ ). The randomness is explained by the variations of the $\mathrm{EH}$ because of the variability of water flow, according to the return period and the river topography. If $\mathrm{Ti}$ is the return period (in years) and $h_{i}$ is the cross-section of the flooded area, Figure 3 indicates that, for the same flooded area, there are different values of $\mathrm{H}_{\text {waterlogging }}$ depending on the discharge and water level associated with each $\mathrm{Ti}(\mathrm{Q}(\mathrm{Ti}))$ in each crosssection. This happens because the water level depth and the roadway centerline height vary along the flooded area.

The EH can be obtained by direct measurement or by simulation according to Figure 4. After calculating the EH, the $\mathrm{H}_{\text {waterlogging }}$ is obtained using (3).

$$
\mathrm{H}_{\text {waterlogging }}=\mathrm{EH}-\mathrm{CR}
$$

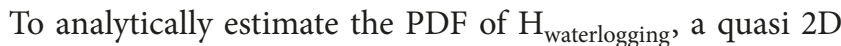
model in which the road cross-section flooded is considered as part of the cross-section of the rivers was used. This way of modelling allows overcoming the limitation of a 1D modelling and at the same time avoid the use of digital elevation models, which not always are available [36]. The procedure considered eight steps:

Step 1. Collect the maximum yearly discharge from available limnimetric or fluviometric stations.

Step 2. Perform a frequency analysis of the time series of maximum discharges and fit the gamma, log normal, and log Pearson II PDFs. The fitting allows estimating the discharge 


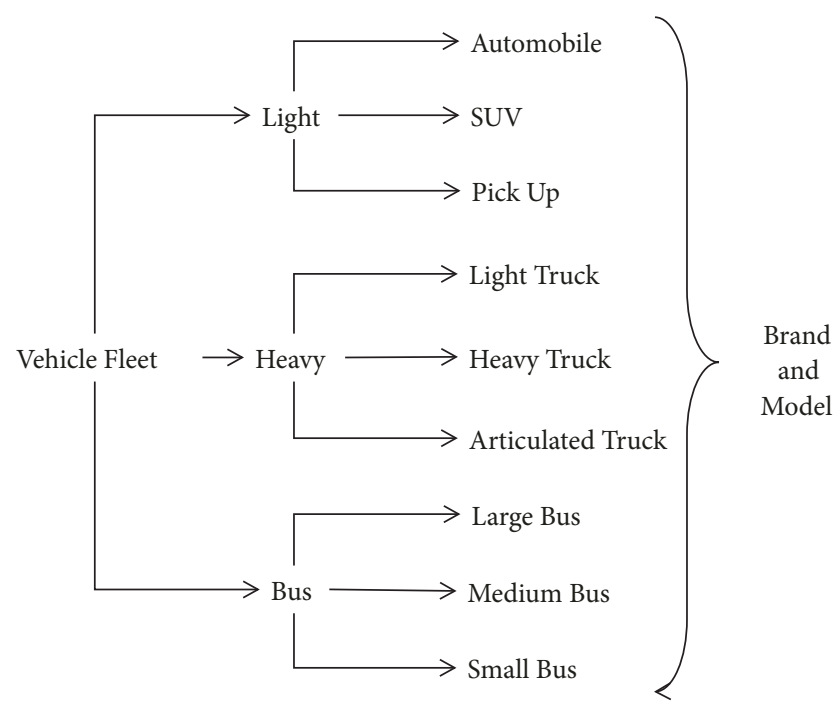

Figure 2: Typical classification of a vehicle fleet.

for different return periods $(\mathrm{Q}(\mathrm{T}))$. The return period can vary between 4 and 500 years. The discharges are grouped in clusters according to different ranges of return periods for obtaining a set of discharges for each range $\left(Q_{i}(T)\right)$, in which " $i$ " represented the $i$-th discharge belonging to each return period range.

Step 3. For each range of return period estimate the percentage of difference $\Delta \mathrm{Q}_{\mathrm{i}}$ (in \%) between the discharge $\mathrm{Q}_{\mathrm{i}}(\mathrm{T})$ and the formative discharge of the river using (4). It represented the discharge increasing over the formative discharge that provoked the overflow. The formative discharge is defined as the most probable flow at a certain recurrence period that shape rivers [37]. It is estimated for a return period of 4 years $\left(\mathrm{Q}_{\mathrm{i}}(\mathrm{T}=4)\right)$ according to Niño [38].

$$
\Delta \mathrm{Qi}=100\left(\frac{\mathrm{Qi}(\mathrm{T})}{\mathrm{Qi}(\mathrm{T}=4)}-1\right)
$$

Step 4. Estimate the maximum percentage of discharge increasing $\left(\Delta \mathrm{Q}_{\mathrm{i}} \max (\mathrm{T})\right)$ based on the flood's return period $\mathrm{T}$ and the percentage of difference $\left(\Delta \mathrm{Q}_{\mathrm{i}}\right)$ using (5).

$$
\Delta \mathrm{Q}_{\mathrm{i}} \max (T)=\max \left[\Delta \mathrm{Q}_{\mathrm{i}}\right]
$$

Step 5. Configure the river cross-section and its properties: dimensions, Manning's coefficients, placement of the road, longitudinal slope of the riverbed, and longitudinal slope of the road (see Figure 7).

Step 6. Estimate the discharge $\mathrm{Qs}_{\mathrm{i}}$ to be used in the simulation of the water level profile using (6). This equation represented the incremental increasing of discharge from the formative discharge according to the increasing of the return period. Considering the cross-section and the longitudinal bedstep of the river, the $\mathrm{Qs}_{\mathrm{i}}$ value allows estimating the water depth (EH of (7)) using hydraulic simulation software.

$$
\mathrm{Qs}_{\mathrm{i}}=\mathrm{Q}_{\mathrm{i}}(\mathrm{T}=4)\left(1+\Delta \mathrm{Q}_{\mathrm{i}} \max (\mathrm{T})\right)
$$

Step 7. Simulate the water level profile for different return periods and discharges $\left(\mathrm{Qs}_{\mathrm{i}}\right)$ and estimating the $\mathrm{H}_{\text {waterlogging }}$ values using (3).

Step 8. For each simulation run obtain the $\mathrm{H}_{\text {waterlogging }}$ values and fit a suitable PDF using the same procedure followed to fit $\mathrm{H}_{\text {wading }}$ values.

3.4. Simulation of the Traffic Interruption Probability Curves. The probability curves estimate the probability that a vehicle cannot circulate on a flooded road because $\mathrm{H}_{\text {waterlogging }}>$ $\mathrm{H}_{\text {wading. }}$. This probability is expressed as $\operatorname{Pr}\left(\mathrm{H}_{\text {waterlogging }}>\right.$ $\left.\mathrm{H}_{\text {wading }}\right)$. To estimate this probability, the FORM was used [39]. The FORM is based on the LSF: $g(X)=G 1(X)-G 2(X)$, in which G1 and G2 are nonlinear functions, and $\mathrm{X}$ is a vector of random variables. $\mathrm{G} 1$ and $\mathrm{G} 2$ are the $\mathrm{PDF}$ of $\mathrm{H}_{\text {waterlogging }}$ and $\mathrm{H}_{\text {wading, }}$, respectively. The traffic interruption probability is defined as $\operatorname{Pr}(\mathrm{g}(\mathrm{X}) \geq 0)$, meaning that $\mathrm{H}_{\text {waterlogging }}>\mathrm{H}_{\text {wading }}$. Given that, in general, $g(X)$ is nonlinear and the PDF of $X$ are nonnormal, therefore, it is necessary to apply a numeric solution for $\mathrm{g}(\mathrm{X}=0)$ based on the Hasofer and Lind [40] procedure and Rossenblatt's [41] transformation to normalize the variables of the vector $\mathrm{X}$. The numerical solution obtains the probability $\beta_{\mathrm{HL}}$ parameter in $\mathrm{g}(\mathrm{X})=0$ for each point of the probability curves using (7). In this equation, $x_{i}$ are the random variables of the vector $\mathrm{X}, \mathrm{u}^{*}$ is the normalized solution of (7), and $\alpha^{*}$ is the normalized vector that describes the normalized LSD $\mathrm{g}(\mathrm{u})=0$. The solution of $(7)$ is the $\beta_{\mathrm{HL}}$, which is an input to estimate the probability using (8).

$$
\begin{aligned}
\beta_{\mathrm{HL}} & =\min _{\{\mathrm{x} \in \mathrm{g}(\mathrm{X})=0\}} \sqrt{\sum_{\mathrm{i}} \mathrm{x}_{\mathrm{i}}^{2}} ; \\
\mathrm{u}^{*} & =-\beta_{\mathrm{HL}} \alpha^{*}=\beta_{\mathrm{HL}}\left(\frac{\partial \mathrm{g} / \partial \mathrm{x}_{\mathrm{i}}}{\sqrt{\sum_{\mathrm{i}=1}^{\mathrm{n}}\left(\partial \mathrm{g} / \partial \mathrm{x}_{\mathrm{i}}\right)}}\right) \\
\mathrm{P}_{\mathrm{int}} & =1-\Phi\left(\beta_{\mathrm{HL}}\right)
\end{aligned}
$$

The probability of (8) represents only one data point of the probability curve of Figure 1 (Box a). Therefore, it is necessary to apply multiple runs with different simulation conditions, which is similar to applying a random sampling on the PDF of $\mathrm{H}_{\text {waterlogging }}$ and $\mathrm{H}_{\text {wading }}$ but considering the consistency of the physical behavior of the flood phenomenon and its effect over the different vehicle classes.

\section{Case Study in the Central Valley of Chile}

The procedure was applied in the Central Valley of Chile (see Figure 5) with the objective of illustrating the proposed procedure to obtain probability curves that allow estimating the traffic interruption probability in that area of the country. The most roads placed in this area are located in floodplains and are exposed to low water level increase during floods that can be assimilating to still water. In the study area, there are 10 fluviometric stations located in Maule, Itata, Bio Bio, and Imperial rivers. Also, 44 ORT are located within the road network of the study area. 


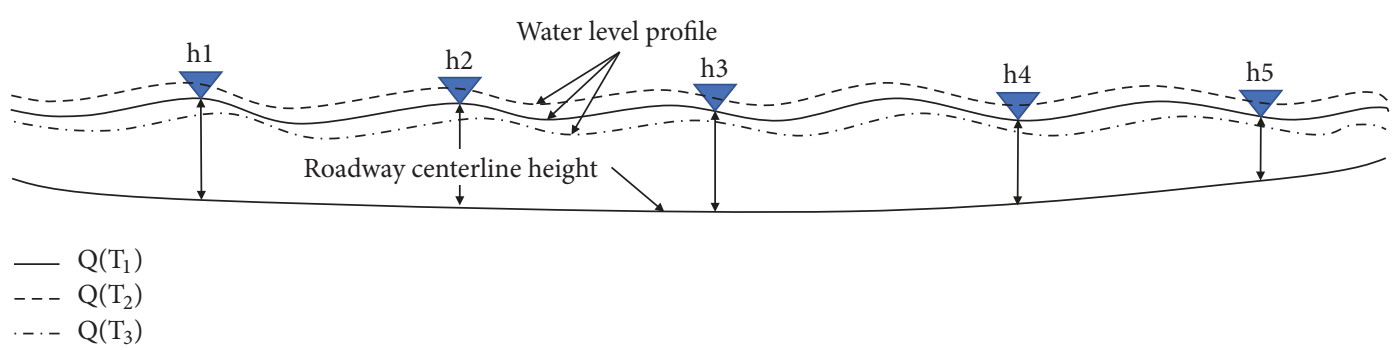

FIGURE 3: Variability of water level depth regarded to different return periods.

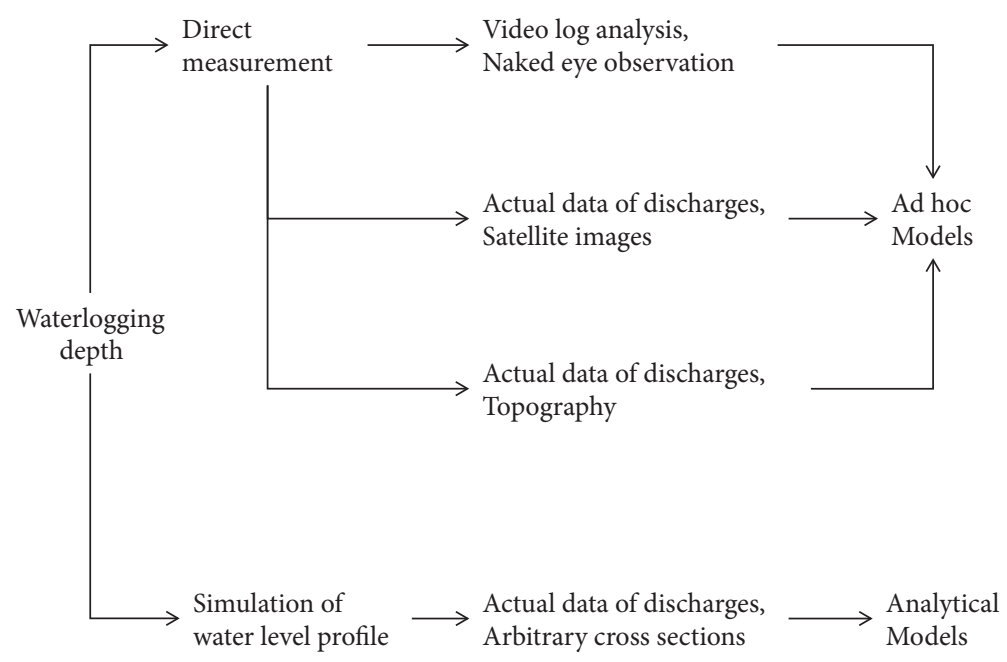

FIGURE 4: Method for obtaining water logging height.

4.1. Wading Height PDF Estimation. A sample of 166,155 vehicles of 3-year records from the ORT provided by the Ministry of Public Works [42] was used to estimate the PDF of $\mathrm{H}_{\text {wading. }}$. Table 1 summarized the sample categorized by vehicle class and subclass. The frequency diagrams are plotted in Figure 6. The software Easy Fit was used to estimate the PDF of $\mathrm{H}_{\text {wading }}$ for each vehicle subclass. Table 2 summarizes the results obtained.

4.2. Estimation of the Probability Density Function of the Waterlogging Height. The input data used to estimate the $\mathrm{H}_{\text {waterlogging }}$ PDF were a generalized river cross-section that included the road cross-section, the maximum yearly discharge data sets, and the parameters used for modelling the water level profile. The geometry of the cross-section is presented in Figure 7. The hydraulic properties used were river Manning's roughness $=0,03$; road surface Manning's roughness $=0,016$; mean slope of the river bottom $=0,0001$ $\mathrm{m} / \mathrm{m}$; road longitudinal slope $=0,5 \%$; and section length $=$ $1000 \mathrm{~m}$.

The discharge data from ten fluviometric stations was provided by the Ministry of Public Works of Chile [43]. Figure 8 plots the maximum yearly discharge (in $\mathrm{m}^{3} / \mathrm{s}$ ) per fluviometric station. The discharge values ranged from 6 to $700 \mathrm{~m}^{3} / \mathrm{s}$ and the discharge records between 5 and 60 .
The frequency analysis of the discharge data is summarized in Table 3 . Using the PDF of Table 3 discharges for return periods $(\mathrm{T})$ of $4,5,10,25,50,100,200$, and 500 years were obtained. The discharge estimated for $\mathrm{T}=4$ was $55 \mathrm{~m}^{3} / \mathrm{s}$ and was considered as the formative discharge in (4).

Discharges obtained for each return period were the input data used to estimate $\mathrm{EH}$, with quasi-2D modelling using the software HEC-RAS 1D. Figure 9 shows the histograms of the $\mathrm{EH}$ obtained, clustered by return period ranges.

The $\mathrm{H}_{\text {waterlogging }} \mathrm{PDF}$ was obtained from the data of Figure 9 by using the Easy Fit software. Table 4 summarized the pdf obtained, classified by return period ranges. All the pdf obtained were normal. The mean and the standard deviation of the PDF are in brackets.

4.3. Traffic Interruption Probability Curves Simulated. To estimate the traffic interruption probability using FORM, a LSF is needed. The LSF was configured using the PDF of $\mathrm{H}_{\text {waterlogging }}$ and $\mathrm{H}_{\text {wading. }}$. The probabilities were obtained using the Hasofer-Lind procedure. The simulation considered 6 vehicle classes and 7 return periods. Figure 10 shows the 42 estimated probability curves.

From Figure 10, three patterns were identified: the interruption probability is similar for light automobiles and SUVs; the single unit heavy trucks and the articulated trucks follow 
TABLE 1: Vehicle sample used to estimate wading height.

\begin{tabular}{lcccc}
\hline Class & Sub-class & \# of vehicle brands & \# of models & Sample \\
\hline \multirow{3}{*}{ Light } & Automobile & 52 & 392 & 87,264 \\
& SUV & 42 & 217 & 41,440 \\
\multirow{2}{*}{ Heavy } & Pick up & 29 & 75 & 31,245 \\
& Single unit light and heavy trucks & 27 & 136 & 3,884 \\
\hline
\end{tabular}

TABLE 2: PDF of wading height of each vehicle class selected in this study.

\begin{tabular}{lcc}
\hline Class & Sub-class & Probability density function (PDF) \\
\hline \multirow{2}{*}{ Light } & Automobile & Normal $(0,4125 ; 0,0232)$ \\
& Pick up & Lognormal3P $(0,606 ; 0,019 ; 0,544)$ \\
& SUV & Lognormal3P $(0,0477 ; 0,0436 ; 0,4496)$ \\
Heavy & Single unit light truck & Lognormal3P $(0,8417 ; 0,0462 ; 0,4789)$ \\
& Single unit heavy truck & Weibull $(1,1323 ; 0,0568 ; 0,6261)$ \\
& Articulated truck & Normal $(1,1986 ; 0,0692)$ \\
\hline
\end{tabular}

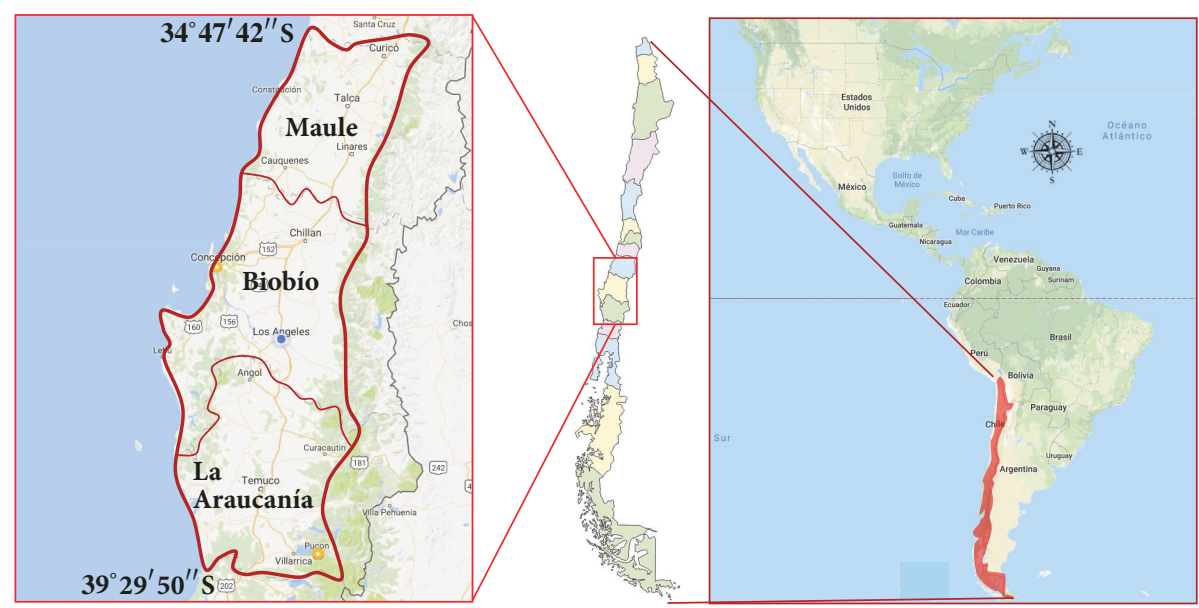

FIGURE 5: Location of the studied area.

TABLE 3: Frequency functions of maximum annual river flows by fluviometric station.

\begin{tabular}{lc}
\hline Fluviometric station & Probability density function \\
\hline Loncomilla in Las Brisas & LogPearson III $(6,5066 ;-0,252 ; 9,634)$ \\
Perquilauquén in Quella & LogPearson III $(4,133 ;-0,379 ; 8,311)$ \\
Perquilauquén in San & LogNormal $(0,105 ; 7,817 ;-1898,7)$ \\
Manuel & LogPearson III $(16,023 ;-0,145 ; 8,667)$ \\
Diguillin Longitudinal & LogNormal $(0,041 ; 8,650 ;-5116,9)$ \\
Itata in Cholguán & Gamma $(5,4995 ; 109,120)$ \\
Duqueco en Villucura & LogPearson III $(7,471 ;-0,229 ; 6,630)$ \\
Mininco in Longitudinal & LogPearson III $(9,546 ;-0,159 ; 7,345)$ \\
Malleco in Collipulli & $\operatorname{LogPearson~III~}(16,266 ;-0,148 ; 7,178)$ \\
Lumaco in Lumaco & LogPearson III $(8,155 ;-0,137 ; 7,885)$ \\
CholChol in Cholchol &
\end{tabular}

TABLE 4: Summary of PDF of $\mathrm{H}_{\text {waterlogging }}$.

\begin{tabular}{lc}
\hline Return period (years) & PDF of $\mathrm{H}_{\text {waterlogging }}$ \\
\hline$[4-5]$ & Normal $(0,0000 ; 0,06430)$ \\
{$[5-10]$} & Normal $(0,1495 ; 0,10903)$ \\
{$[10-25]$} & Normal $(0,3923 ; 0,09948)$ \\
{$[25-50]$} & Normal $(0,6099 ; 0,09327)$ \\
{$[50-100]$} & Normal $(0,7783 ; 0,07420)$ \\
{$[100-200]$} & Normal $(0,9371 ; 0,08670)$ \\
{$[200-500]$} & Normal $(1,0888 ; 0,07054)$ \\
\hline
\end{tabular}

a similar pattern; and the traffic interruption probability of automobiles and SUVs is higher than the same probability for single unit heavy trucks and articulated trucks. This 


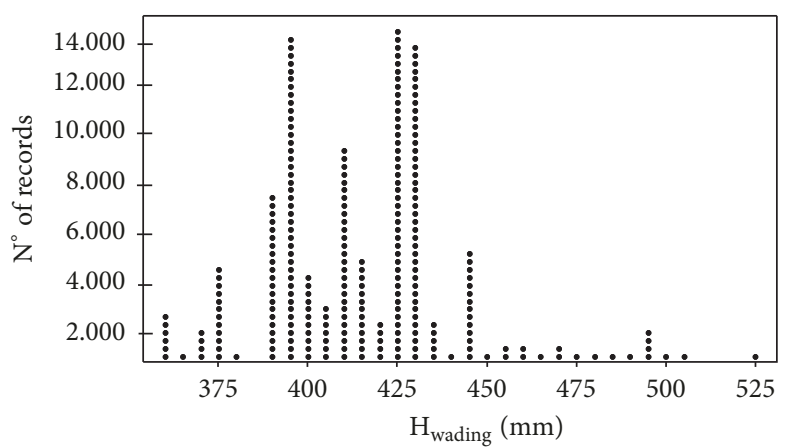

(a)

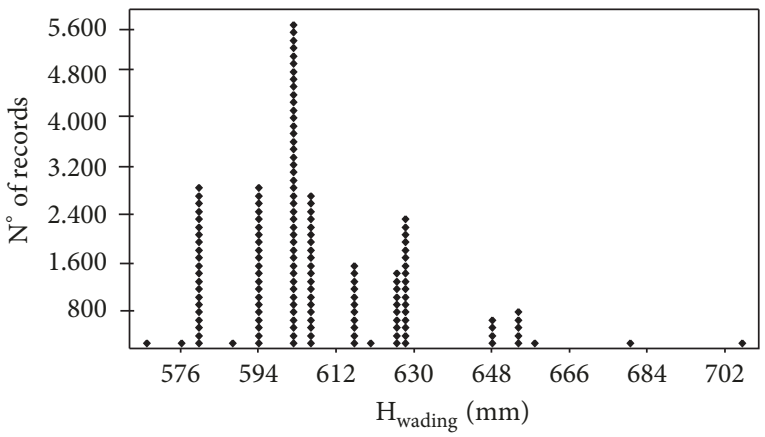

(c)

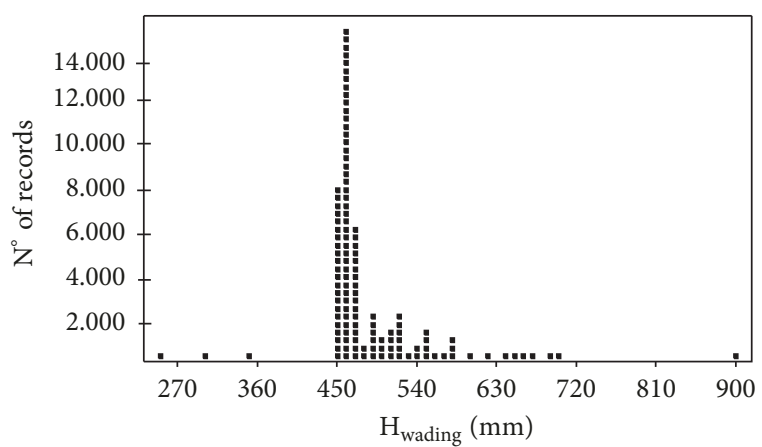

(b)

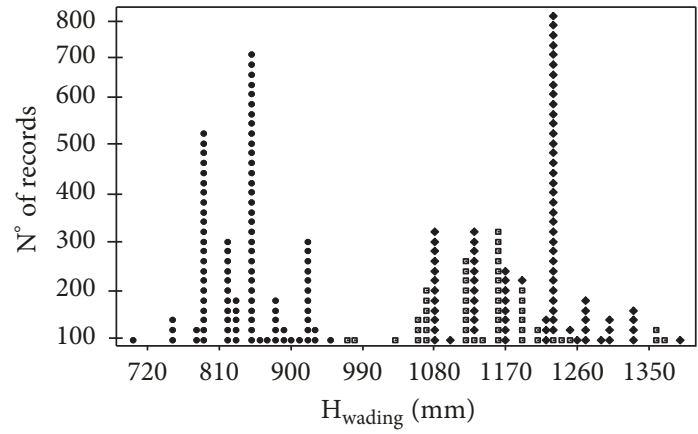

- Articulated truck

- Single unit heavy truck

- Single unit light truck

(d)

FIGURE 6: Histograms of wading height per vehicle class. (a) Automobile (each dot $=346$ data points). (b) SUV (each dot $=386$ data points). (c) Pick-up (each dot = 127 data points). (d) Heavy vehicles (each dot $=30$ data points).

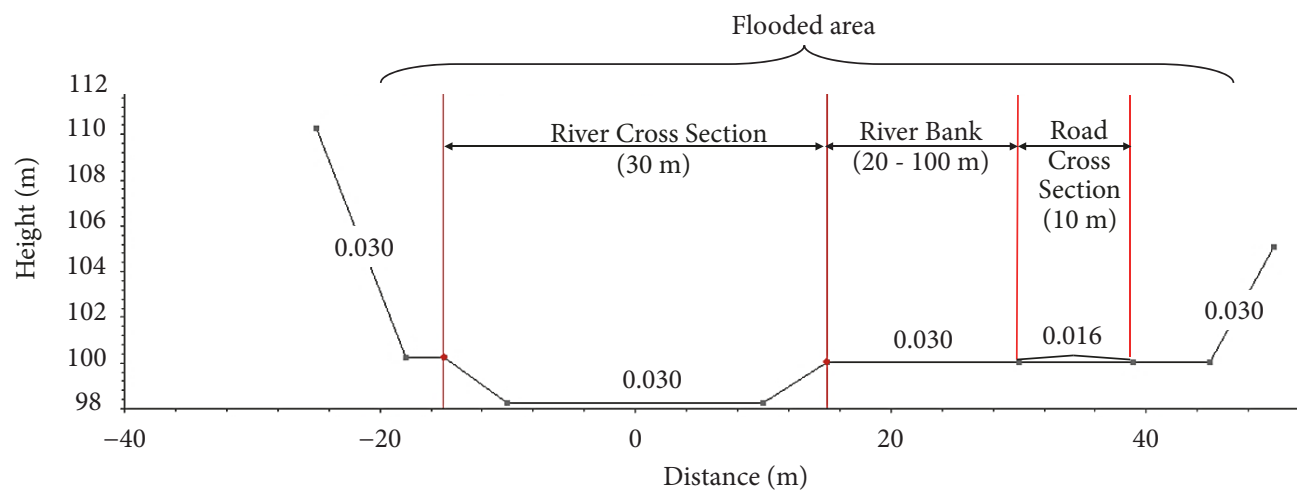

FIGURE 7: Cross-section geometry used for modelling the water level.

result is logical and proves the coherence of the model developed. Using the PDF curves of Figure 10 two values of $\mathrm{H}_{\text {waterlogging }}$ were obtained: (a) the limit waterlogging depth that is defined as the depth at which the traffic interruption probability is 1,0 and (b) the alert waterlogging depth associated with a traffic interruption probability of 0,5 . Both values of $\mathrm{H}_{\text {waterlogging }}$ can be used to establish an alert system for drivers based on the properties of the local vehicle fleets. Results are summarized in Table 5 per vehicle subclass.

\section{Conclusions}

The aim of this paper was to propose a procedure based on reliability principles to estimate the traffic interruption probability due to road waterlogging considering very lowspeed flow. The proposed procedure was applied in the south of Chile. A data set of 166,155 vehicles and records up to 30 years of discharge data of ten fluviometric stations were used and a total of 42 probability curves were obtained. In this context, the following conclusions were obtained: 


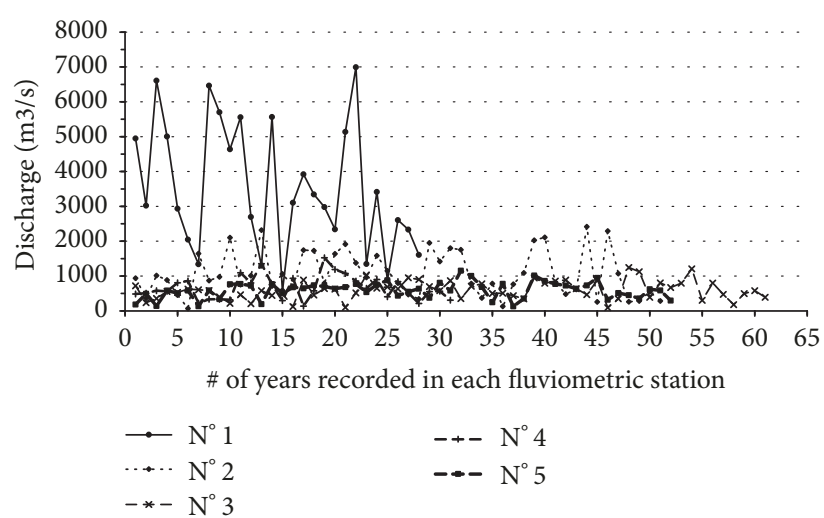

(a)

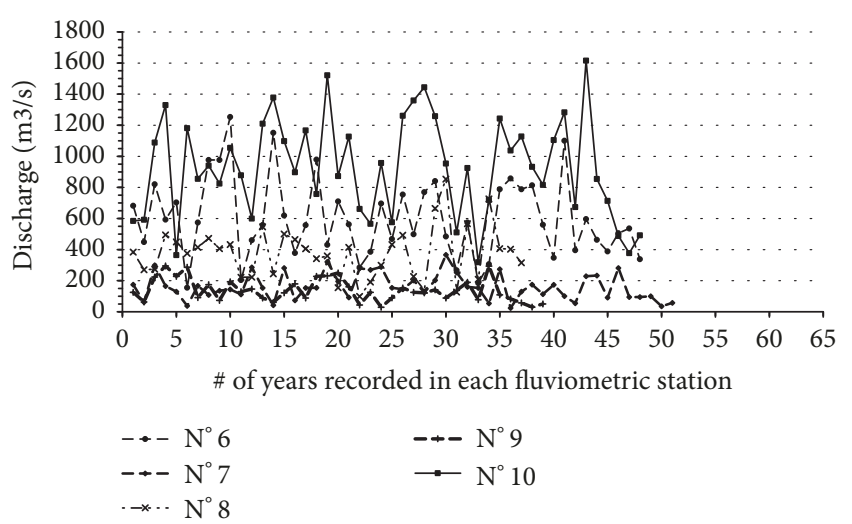

(b)

FIgURE 8: Maximum yearly discharge per fluviometric station. (a) Fluviometric stations 1 to 5. (b) Fluviometric stations 6 to 10.

TABLE 5: Limit and alert $\mathrm{H}_{\text {waterlogging }}$ per vehicle subclass.

\begin{tabular}{lcc}
\hline \multirow{2}{*}{ Vehicle subclass } & \multicolumn{2}{c}{$\mathrm{H}_{\text {waterlogging }}(\mathrm{m})$} \\
\hline Automobile & 0,73 & Alert \\
SUV & 0,77 & 0,41 \\
Pick-up & 0,88 & 0,46 \\
Single unit light truck & 1,14 & 0,57 \\
Single unit heavy truck & 1,44 & 0,83 \\
Articulated truck & 1,53 & 1,13 \\
\hline
\end{tabular}

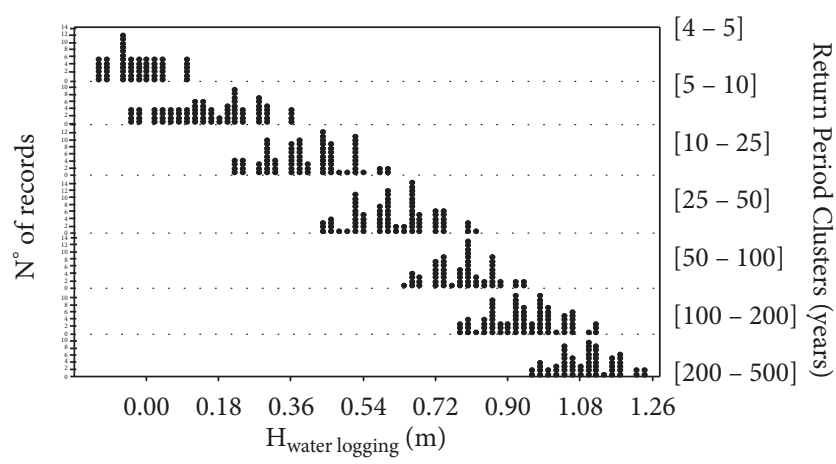

FIGURE 9: Summary of waterlogging height clustered according to return time.

Results obtained show that the waterlogging depth that interrupts traffic with a probability of 1,0 varies between 0,73 and $0,88 \mathrm{~m}$ for light vehicles and between 1,14 to 1,53 $\mathrm{m}$ for heavy vehicles. Likewise, the waterlogging depth that interrupts traffic with a probability of 0,5 varies between 0,41 and $0,57 \mathrm{~m}$ for light vehicles and between 0,83 to $1,20 \mathrm{~m}$ for heavy vehicles. These values are higher than the values reported in the literature that varies between 0,3 and 0,5 for light vehicles in still waters.
The waterlogging depth estimated in this study is valid only for still waters, in which the protection of the HVAC system is more relevant than the vehicle stability. At high speed flows, for instance, higher than $1 \mathrm{~m} / \mathrm{s}$, the stability turns more relevant and leads to the waterlogging depth being reduced compared to the estimated in this study.

The literature about the effect of waterlogging on road networks used simplified methods to obtain the vehicle's wading height; this is because those literature studies were supported by direct in-field observation, which leads to using small sample sizes. This limitation has been resolved in this research by incorporating the variability of the vehicle's wading height and a large sample of vehicles obtained from records of existent open road tolls in Chilean highways.

Areas of potential flooding can be identified by superimposing flood-prone areas onto road network maps. Based on the composition of the traffic and the probability curves developed in this study, it is possible to analyze the cost of rerouting to justify the implementation of flood protection measures in the road network; therefore, the results obtained are useful for road managers to estimate the budget needed to mitigate the effect of floods on the road network.

For simplicity, the water level profile was obtained using a quasi-two-dimensional modelling, which does not permit incorporating the velocity of the water and its effect on the stability of the vehicles. For that reason, the model is valid only for still waters. To refine the model, a two-dimensional modelling is needed in order to incorporate the effect of water flow speed on the vehicles' stability using hydrodynamic models combined with reliability principles.

The probability curves have enough generality to be used in traffic management policies in flood-prone areas and also demonstrate the need for technical evaluation of need for works of protection against flooding. The critical and limit waterlogging depths calculated are representative of the Central Valley of Chile. To apply this to other areas of the country, only the PDF of the EH would need to be modelled, because the PDF of waterlogging depth is representative of the entire country. 


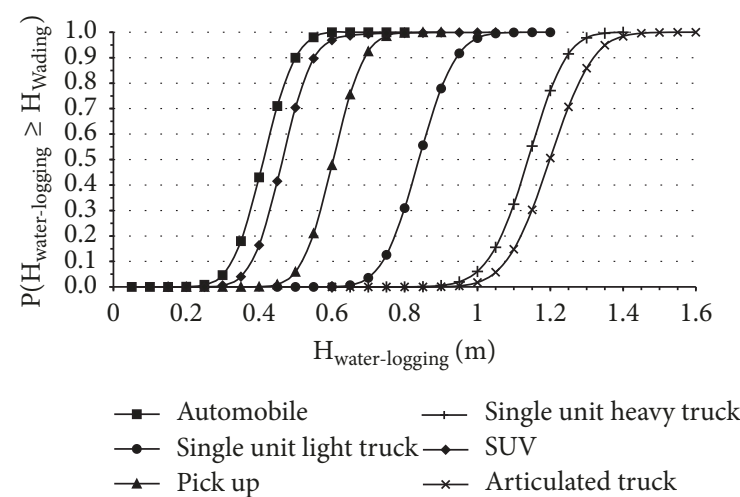

(a)

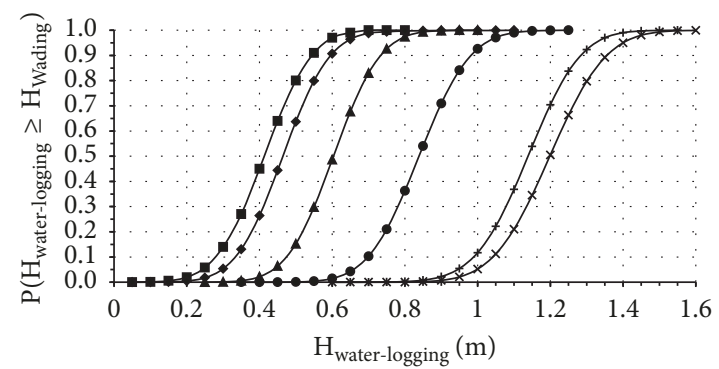

$\rightarrow$ Automobile $\quad \longrightarrow$ Single unit heavy truck $\rightarrow$ Single unit light truck $\rightarrow$ SUV

$\rightarrow$ Pick up $\quad *$ Articulated truck

(c)

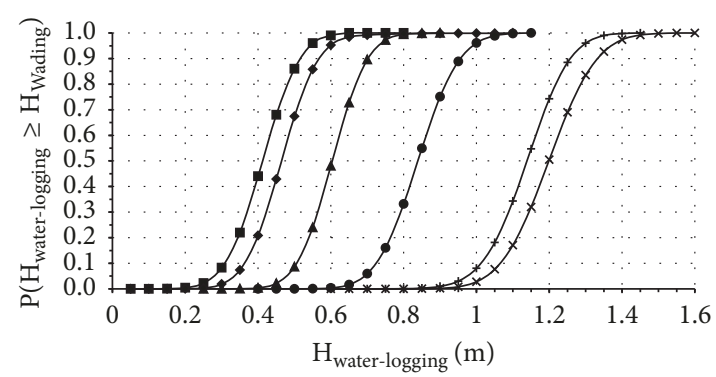

$\begin{array}{ll}\rightarrow \text { Automobile } & \rightarrow \text { Single unit heavy truck } \\ \rightarrow-\text { Single unit light truck } \rightarrow \text { SUV } & \rightarrow \text { Articulated truck }\end{array}$

(e)

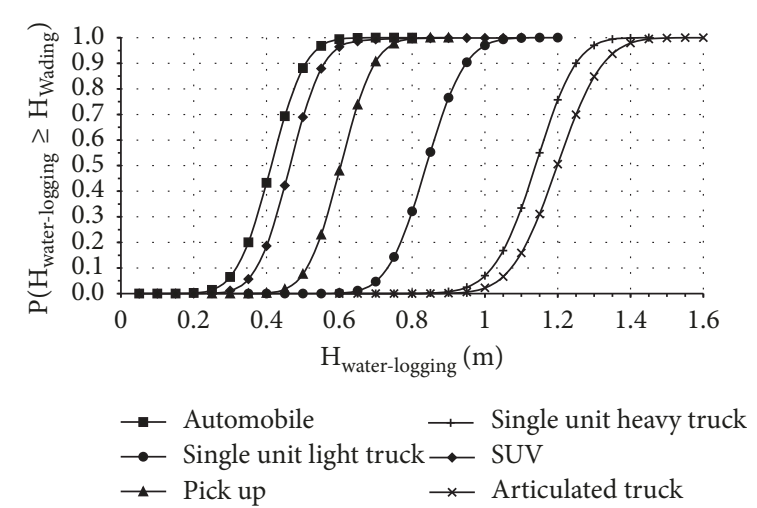

(g)

FIGURE 10: Interruption probability curves simulated per return period and vehicle subclass. (a) $4<\mathrm{T}<5$ years. (b) $5<\mathrm{T}<10$ years. (c) $10<$ $\mathrm{T}<25$ years. (d) $25<\mathrm{T}<50$ years. (e) $50<\mathrm{T}<100$ years. (f) $100<\mathrm{T}<200$ years. (g) $200<\mathrm{T}<500$ years.

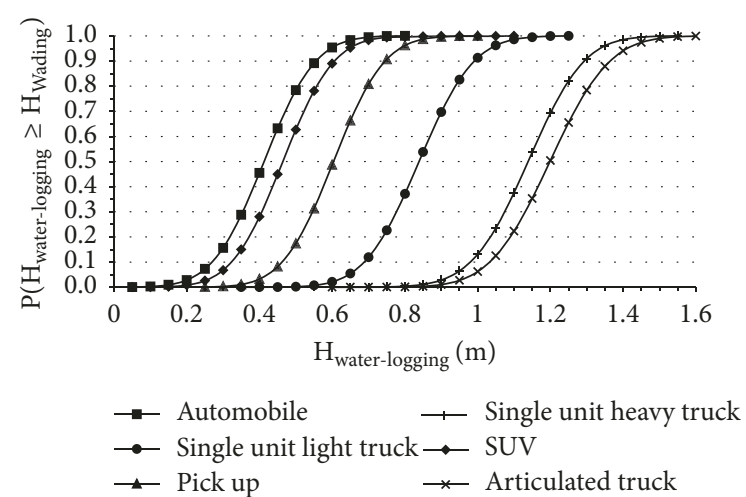

(b)

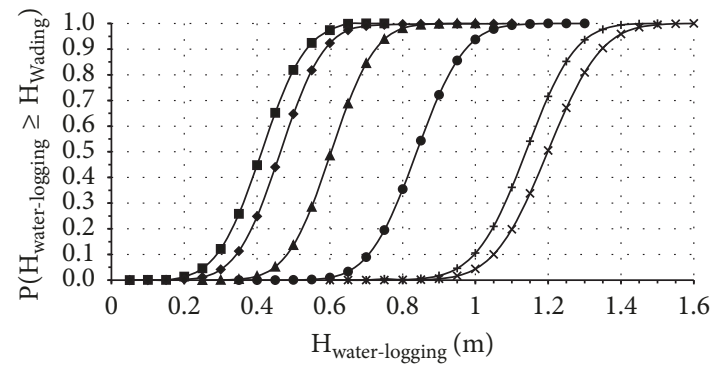

$\rightarrow$ Automobile $\rightarrow$ Single unit heavy truck
$\rightarrow$ Single unit light truck $\rightarrow$ SUV
$\rightarrow$ Pick up $\quad \rightarrow$ Articulated truck

(d)

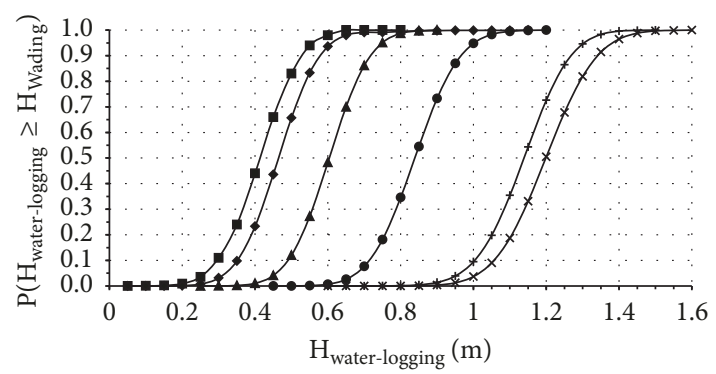

$\rightarrow$ Automobile $\quad \longrightarrow$ Single unit heavy truck
$\rightarrow$ Single unit light truck $\rightarrow$ SUV
$\simeq$ Pick up

(f) 


\section{Data Availability}

The data used to support the findings of this study are available from the corresponding author upon request.

\section{Conflicts of Interest}

The authors declare that they have no conflicts of interest.

\section{Acknowledgments}

The authors wish to thank the National Commission for Science and Technology (CONICYT) of Chile for supporting the research projects FONDEF ID14I20309 and thank the National Research Center for Integrated Natural Disaster Management (CIGIDEN), CONICYT/FONDAP/15110017, within which this paper was prepared. The authors also wish to thank the Ministry of Public Works of Chile for providing the data used for the research presented in this paper.

\section{References}

[1] W. Kron, "Flood Risk= Hazard $*$ Values $*$ Vulnerability," Water International, vol. 30, no. 1, pp. 58-68, 2005.

[2] TRB, Highways Capacity Manual, Transportation Research Board, 2016.

[3] M. Gall, B. J. Boruff, and S. L. Cutter, "Assessing flood hazard zones in the absence of digital floodplain maps: Comparison of alternative approaches," Natural Hazards Review, vol. 8, no. 1, pp. 1-12, 2007.

[4] O. Petrucci and A. A. Pasqua, "Damaging events along roads during bad weather periods: A case study in Calabria (Italy)," Natural Hazards and Earth System Sciences, vol. 12, no. 2, pp. 365-378, 2012.

[5] P.-A. Versini, E. Gaume, and H. Andrieu, "Assessment of the susceptibility of roads to flooding based on geographical information - Test in a flash flood prone area (the Gard region, France)," Natural Hazards and Earth System Sciences, vol. 10, no. 4, pp. 793-803, 2010.

[6] ICPR, Atlas of Flood Danger and Potential Damage Due to Extreme Floods of The Rhine, International Commission for the Protection of the Rhine, Koblenz. Germany.

[7] USACE, "HEC-RAS v. 5.0.3," Tech. Rep., U.S. Army Corps of Engineers, 2016.

[8] DHI, MIKE11 A Modelling System for Rivers and Channels - Reference Manual, DHI Water \& Environment, Hørsholm, Denmark, 2002.

[9] S. Patro, C. Chatterjee, S. Mohanty, R. Singh, and N. S. Raghuwanshi, "Flood inundation modeling using MIKE FLOOD and remote sensing data," Journal of the Indian Society of Remote Sensing, vol. 37, no. 1, pp. 107-118, 2009.

[10] E. Bladé, L. Cea, G. Corestein et al., "Iber: a tool for the numerical simulation of river flow," Revista Internacional de Métodos Numéricos para Cálculo y Diseño en Ingeniería, vol. 30, no. 1, pp. 1-10, 2014.

[11] DHI, MIKE FLOOD 1D-2D MODELLING - User manual, DHI Water \& Environment, Hørsholm, Denmark, 2003.

[12] DHI, MIKE 3 Estuarine and Coastal Hydraulics and Oceanography-Short Description, DHI Water \& Environment, Hørsholm, Denmark, 2001.
[13] USACE, HEC-FDA: Flood Damage Reduction Analysis, U.S. Army Corps of Engineers, 2016.

[14] FEMA, "Multi-hazard loss estimation methodology. Flood Model HAZUS ${ }^{\circledR}$ MH MR4," Technical Manual, Federal Emergency Management Agency, 2003.

[15] F. Klijn, P. J. A. Baan, K. M. De Bruijn, and J. Kwadijk, Overstromingsrisicos in Nederland in een veranderend klimaat, WL delft hydraulics, WL delft hydraulics, Delft, Netherlands, 2007.

[16] W. Vanneuville, R. Maddens, C. Collard, P. Bogaert, P. de Maeyer, and M. Antrop, "Impact op mens en economie t.g.v. overstromingen bekeken in het licht van wijzigende hydraulische condities, omgevingsfactoren en klimatologische omstandigheden," Tech. Rep. MIRA/2006/02, Universiteit Gent, Belgium, 2006.

[17] E. C. Penning-Rowsell, C. Johnson, S. Tunstall et al., The Benefits of Flood And Coastal Risk Management: A Handbook of Assessment Techniques, Flood Hazard Research Centre. Middlesex University Press, 2005.

[18] M. Kyte, Z. Khatib, P. Shannon, and F. Kitchener, "Effect of weather on free-flow speed," Transportation Research Record, no. 1776, pp. 60-68, 2001.

[19] B. L. Smith, K. G. Byrne, R. B. Copperman, S. M. Hennessy, and N. J. Goodall, "An investigation into the impact of rainfall on freeway traffic flow," in Proceedings of the Proceedings 83th Annual Meeting of the Transportation, Washington, Wash, USA, 2004.

[20] M. Agarwal, T. H. Maze, and R. Souleyrette, "Impacts of weather on urban freeway traffic flow characteristics and facility capacity," in Proceedings of the 2005 Mid-Continent Transportation Research Symposium, pp. 18-19, Ames, Iowa, USA, 2005.

[21] R. Hranac, E. Sterzin, D. Krechmer, H. Rakha, and M. Farzaneh, Empirical Studies on Traffic Flow in Inclement Weather, Federal Highway Administration, Washington, Wash, USA, 2006.

[22] M. Sabir, J. van Ommeren, M. J. Koetse, and P. Rietveld, Welfare Effects of Adverse Weather through Speed Changes on Car Commuting Trips, Vu University, Amsterdam, Netherlands.

[23] I. Tsapakis, T. Cheng, and A. Bolbol, "Impact of weather conditions on macroscopic urban travel times," Journal of Transport Geography, vol. 28, pp. 204-211, 2013.

[24] E. Hooper, L. Chapman, and A. Quinn, "Investigating the impact of precipitation on vehicle speeds on UK motorways," Meteorological Applications, vol. 21, no. 2, pp. 194-201, 2014.

[25] M. Pregnolato, A. Ford, S. M. Wilkinson, and R. J. Dawson, "The impact of flooding on road transport: A depth-disruption function," Transportation Research Part D: Transport and Environment, vol. 55, pp. 67-81, 2017.

[26] T. D. Shand, R. J. Cox, M. J. Blacka, and G. P. Smith, "Appropriate safety criteria for vehicles. Revision Project 10 . Stage 2. Literature Review," Tech. Rep., Australian Rainfall and Runoff, Australia, 2010.

[27] F. Y. Teo, J. Xia, R. A. Falconer, and B. Lin, "Experimental studies on the interaction between vehicles and floodplain flows," International Journal of River Basin Management, vol. 10, no. 2, pp. 149-160, 2012.

[28] J. Xia, R. A. Falconer, X. Xiao, and Y. Wang, "Criterion of vehicle stability in floodwaters based on theoretical and experimental studies," Natural Hazards, vol. 70, no. 2, pp. 1619-1630, 2014.

[29] J. Xia, F. Teo, R. Falconer, Q. Chen, and S. Deng, "Hydrodynamic experiments on the impacts of vehicle blockages at bridges," Journal of Flood Risk Management, vol. 11, pp. S395-S402, 2018. 
[30] E. Martínez-Gomariz, M. Gómez, B. Russo, and S. Djordjević, "A new experiments-based methodology to define the stability threshold for any vehicle exposed to flooding," Urban Water Journal, vol. 14, no. 9, pp. 930-939, 2017.

[31] M. Kramer, K. Terheiden, and S. Wieprecht, "Safety criteria for the trafficability of inundated roads in urban floodings," International Journal of Disaster Risk Reduction, vol. 17, pp. 7784, 2016.

[32] E. Martínez-Gomariz, M. Gómez, B. Russo, and S. Djordjević, "Stability criteria for flooded vehicles: a state-of-the-art review," Journal of Flood Risk Management, vol. 11, pp. S817-S826, 2018.

[33] K. Pyatkova, A. S. Chen, S. Djordjevic et al., "Flood impacts on road transportation using microscopic traffic modelling technique," in Proceedings of the SUMO User Conference, Berlin, Germany, 2015.

[34] J. Yin, D. Yu, Z. Yin, M. Liu, and Q. He, "Evaluating the impact and risk of pluvial flash flood on intra-urban road network: A case study in the city center of Shanghai, China," Journal of Hydrology, vol. 537, pp. 138-145, 2016.

[35] J. Affum, G. Giummarra, and H. Cheung, "Safety provisions for floodways over roads," Austroads Report AP-R481-15, 2015.

[36] L. M. Timbe and P. Willems, "Desempeño de modelos hidráulicos 1D y 2D para la simulación de inundaciones," Maskana, vol. 2, no. 1, pp. 91-98, 2015.

[37] M. Bolla Pittaluga, R. Luchi, and G. Seminara, "On the equilibrium profile of river beds," Journal of Geophysical Research: Earth Surface, vol. 119, no. 2, pp. 317-332, 2014.

[38] Y. Niño, River Hydraulic and Sediment Transport, Universidad de Chile, Chile, 2004.

[39] A. Haldar and S. Mahadevan, Probability, Reliability and Statistical Methods in Engineering Design, Wiley, New York, NY, USA, 1st edition, 2000.

[40] A. M. Hasofer and N. C. Lind, "An exact and invariant first order reliability format," Journal of Engineering Mechanical, vol. 100, pp. 111-121, 1974.

[41] M. Rosenblatt, "Remarks on a multivariate transformation," Annals of Mathematical Statistics, vol. 23, pp. 470-472, 1952.

[42] MOP, Basic Study on Update HDM-4 Parameters, Ministry of Public Works, Chile, 2017.

[43] MOP, Información Oficial Hidrometeorológica y de Calidad de Aguas en Línea, MOP, Chile, 2016, http://snia.dga.cl/ BNAConsultas/reportes. 


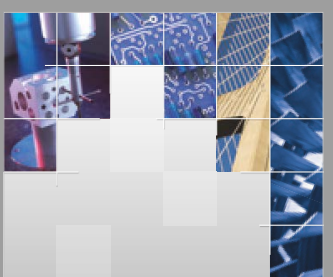

\section{Enfincering}
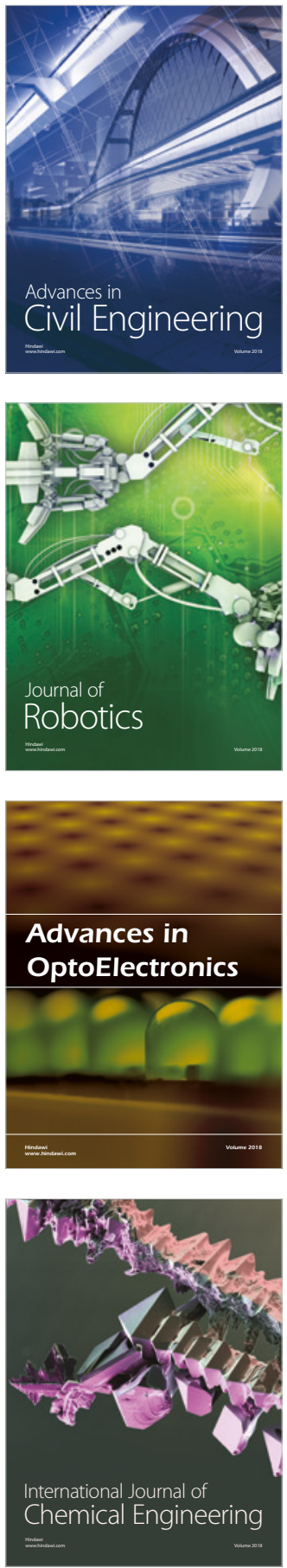

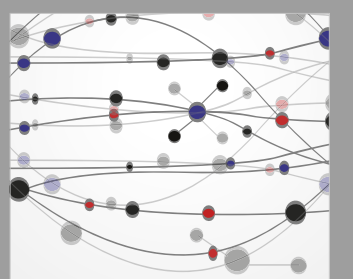

\section{Rotating \\ Machinery}

The Scientific World Journal

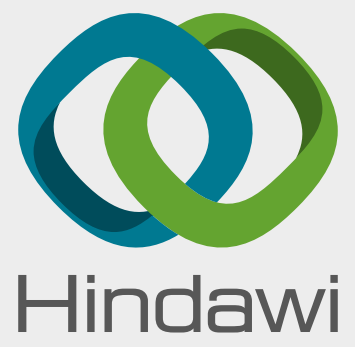

Submit your manuscripts at

www.hindawi.com
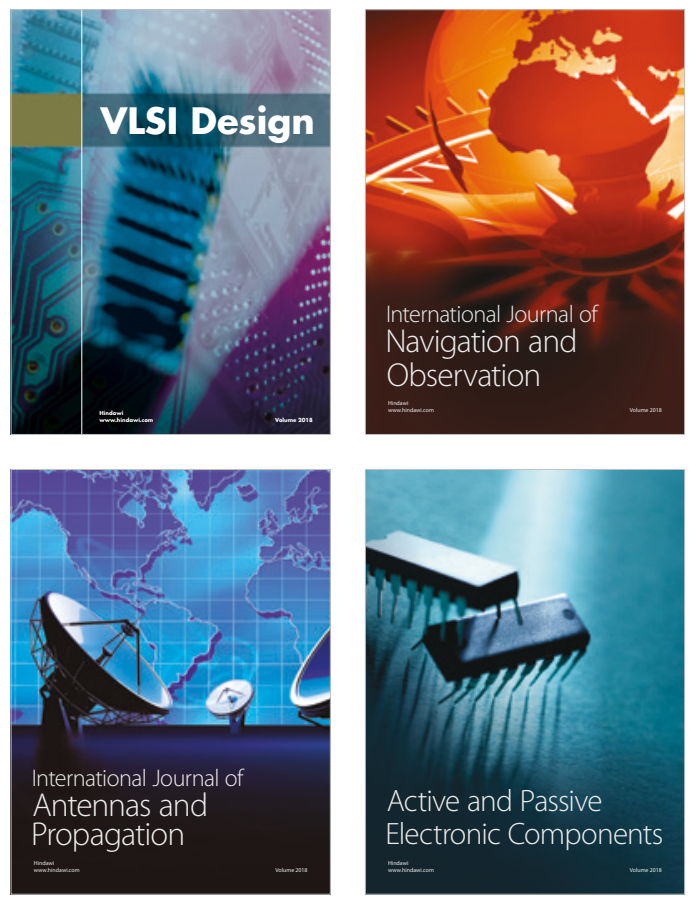
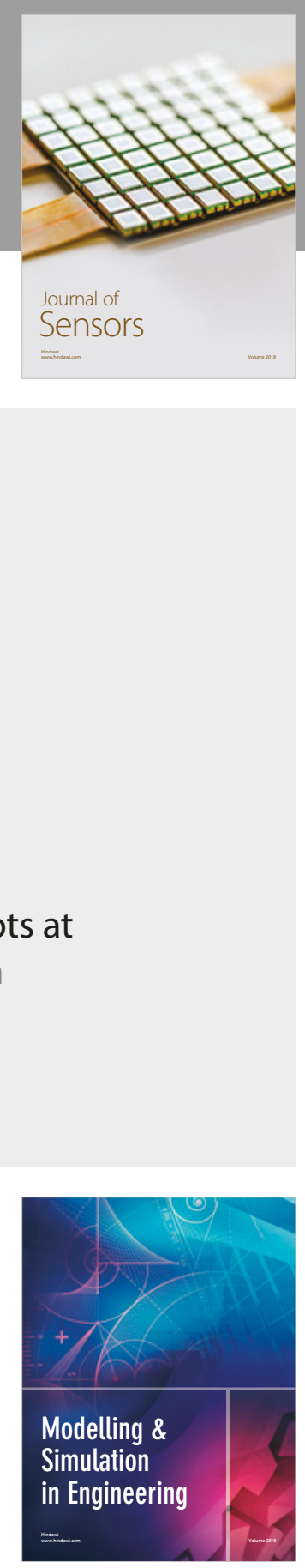

\section{Advances \\ Multimedia}
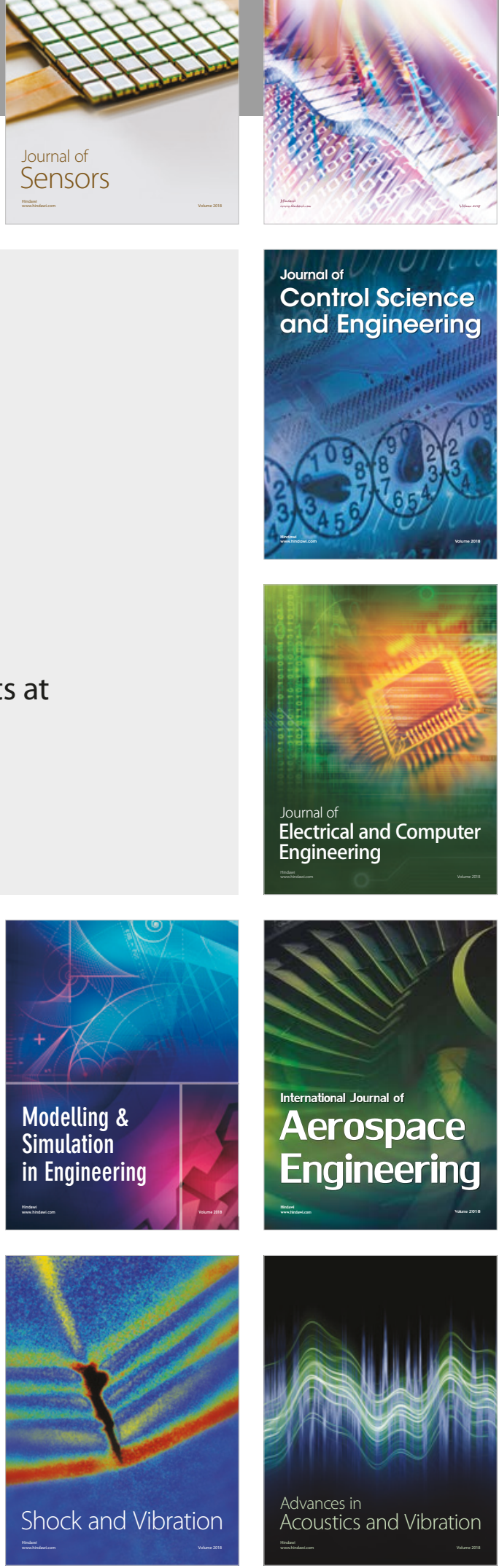